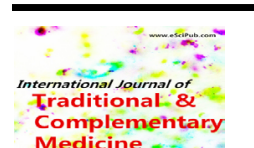

International Journal of Traditional and Complementary Medicine Medicine

A paer ravewowod Journal

(ISSN:2474-1361)

\title{
The milk - cheese cycle with alpha emitters - pulmonary contribution to the refeeding of the hormonal system in unoptimal conditions
}

\section{Florent Pirot}

Unaffiliated researcher, 06560 Valbonne, France

\begin{abstract}
There is a material truth behind the expression "French people are cheese-eating surrendering monkeys" that involves the higher natural radioactivity in France (averaged) in comparison with the USA, the United Kingdom, Spain and Poland. This comes from the hormone loss related to internal alpha emitting nanoparticulate contamination and involves a compensation with among other things milk drinking and cheese eating. The basic hormone loss can be related to the "surrendering" reputation entirely (testosterone for instance was shown to be destroyed in uranium miners). A secondary cycle emerges to re-establish the sexual difference, where women in these regions typically drink fresh milk whereas men typically eat cheeses that have stayed long in caves and where the hormones have disappeared. This is globally spontaneous. Inhalation of cheese odors serve for cerebral confirmation that hormones have disappeared. That general theorem is a subpart of what was already denominated earlier the meat-pollution cycle for reasons of desire to adopt an easily memorizable name, due to the essentiality of the concept for humankind.
\end{abstract}

Keywords: alpha emitting nanoparticulates, hormone disruption, How to cite this article:

Florent Pirot.The milk - cheese cycle with alpha emitters pulmonary contribution to the refeeding of the hormonal system in unoptimal conditions. International Journal of Traditional and Complementary Medicine 2021, 6:38.

oestrogens, testosterone, dairy industry, endocrine disruption, uranium mining, depleted uranium 


\section{Introduction}

The visit of the village of Vestmannaeyjabaer by the author ten years ago led to atonishment in front of very old-style "Milk is good" placards near the soccer stadium. The campaign for milk drinking in Nordic countries was said to be related to the surplus in production that had to be consumed quickly. The fact is that these placards have no equivalent, in their old style and perseverance on the walls, indicating another experience that defintively has to be related to the 1973 volcanic eruption, and its ash. The disaster that was experimented by the villagers was faced by a small army of ashremovers and, certainly, those that were milkdrinkers achieved better efficiency in front of the ash. This comes from the issue of alphaemitting nanoparticulates in volcanic dust. Milk proteins, inside the body, demand alpha decay to be broken and digested (this is akin to meat proteins - see [1]). This local experience obviously stayed in the local memories. Secondly, the fishing industry leads as well to exposure to varying levels of natural alpha emitters from the oceanwater (with winds and waves in particular, as well as in the handling of fish) and the island is the top haven for the fishing industry in Iceland.

This situation relates milk drinking to traditional industries (and it can be noted how the general reputation of the fishing industry as the industry with lowest life expectancies directly relates to the very high levels of alpha emitters in oceanwaters - accidents fostered by neurological disorders associated with internal contamination for instance, traumatic brain injury-related (see for instance [2] for a summary)). It is also possible to envision it for girls in Iceland (country, in general of very low natural radioactivity), to a certain proportion of boys.

\footnotetext{
Deliberate oestrogenization with soy milk (phytooestrogens) was a frequent practice of the author through his works on Sismondi in the middle of an economics lab of the public sector, in St Etienne in France,
}

The observational frames, below, give account of areas with higher natural radioactivity, and cases with artificial contamination. The phenomena cannot be related to the particular experience of Iceland's inhabitants.

\section{Explaining the tradition}

The hormonal suppression from internal contamination with alpha emitters was identified in ${ }^{[3]}$ in a very significant way, with uranium miners and testosterone loss. The most likely explanation is that the testosterone associated with the physical effort of the miners circulating in the blood to irrigate the various receptors is met by internal contamination with alpha emitters, in the blood, where the alpha decays, and later shuriken ${ }^{[4]}$ spins under sunray exposure (with solar energy also pushing the shurikens) destroy the testosterone in throves. A secondary explanation would relate to testosterone produced by internal consciousness, nationalistically that "African uranium is being taken away from us Africans", and that testosterone identically destroyed by the internal contamination, alpha decay and shuriken effect (for instance this time in the blood vessels of the brain).

The health situation in areas of high natural radioactivity, and the relation of the inhabitants of these areas to cheese and dairy has to be analyzed through the same pattern, in a tamed way. The milk / cheese consumption patterns acquire a sexualized oscillation that has to be related to hormones in milk and cannot be assimilated to the Scandinavian campaigns for milkdrinking (where the invention of the neutral pronoun Hen in Sweden, taken from the Finnish language, confirms the pattern) ${ }^{1}$.

The traditional cheese eating in Auvergne and Corsica, for instance is a direct indicator of a pattern that can be both related to the high natural radioactivity, and to resexualization. Hormones in milk serve for women to

to achieve the meditative state needed, while soccer matches were a main topic of discussion of other people in the lab. 
resexualize, by stimulating breast inflation for instance. This can be tested even with lactoserum. One of the cases observed by the author involves a region where the radioactivity is naturally quite low but where pollution with depleted uranium happened; a young woman that presents clear signs of internal contamination was observed ritualistically drinking fresh milk. US whole milk retail prices have started to rise again in September 2018 after the beginning of the Brunswick nuclear accident (presented in ${ }^{[5]}$ ), the rise (of circa $8 \%$ ) ending in March 2020².

The resexualization is achieved by men who differenciate by eating worn out cheeses, where these hormones have disappeared. Pulmonary inhalation while choosing the cheese allows careful selection of the product. The most worn out cheeses are traditional products of areas with very high natural radioactivity - such as Cantal, Roquefort, Fourme d'Ambert and Corsican cheeses. The open market system (in streets on market days) is a particularly popular moment of cheese selection for the customers. Unaccustomed people talk of "feet-smelling cheeses", describing them indeed through an area of the body that is not a vector of sexual hormones. Men, essentially, are the consumers whereas traditionally women milking the cows are also the drinkers of milk.

There is a varsity of effects of internal contamination with alpha emitters that can be associated with strong needs to re-hormonize in a sexualized way. The internal contamination with alpha emitters does not only damage and destroy hormones within the blood but can also attack directly the gonads and glands where hormones are produced, testicles, ovaries ${ }^{[6]}$, and in the brain. Alpha decay and the shuriken effect (activated by radiation) can damage and destroy any cell at range. Not only milk is an easy source of protein in regions with low fertility (because of that high natural radioactivity), but it brings a direct hormone compensation, appreciated on the morning by women (to

\footnotetext{
${ }^{2}$ BLS monthly retail whole milk prices data quoted in Difficult times for US dairy, October 2020, PWC
}

compensate the nightly time of radioactive decay uncompensated by any food intake). Worn out cheeses have become a typically French tradition because of the higher natural radioactivities in France, in comparison with all its geographic neighbours. A 2012 news report from Pinedale Online in Wyoming indicated worries of a threat on roquefort production in France, from wolves attacks on the sheep. In 1899 in the Elk Mountain Pilot (archive of Colorado Historic Newspapers), was published the exact recipe of the roquefort. This shows an existing demand for French worn out cheeses in these areas of high natural radioactivity.

As concerns the eggs industry, there also is a pattern of re-hormonization through their consumption that depends from cooking levels. The hormones in eggs also depend on the environment of the poultry (see ${ }^{[7]}$ ). Certainly this explains why, structurally "hen" is the neutral pronoun in Swedish.

\section{Discussion}

This presents an equilibrium, reachieved in contexts of suboptimal conditions. It is obviously linear with the levels of internal contamination. It remains that there are subsequent psychological factors of dairy intakes that have to be taken into account. Certainly a vast number of men consume milk products with the psychological idea it is a key criteria for sperm production, considering they need vast flows of sperm to impress the partner in the sexual intercourse. This, nevertheless is not a factor in the preference for worn out cheeses over milk. A "recipe for sperm" given by a pornography actor in a documentary video included milk and eggs in a shaker.

The dairy industry is in a certain way anchored to this radioactivity-fueled consumption but depollution efforts that mechanically deprieve it of profits would have to be counterbalanced by the low added value of that industry, by the space taken by these farm ranges and by the extremely ancient and still successful experiment, in India, where cows actually live in 
the middle of cities. The metals used for the farms (containment structures for the animals) could simply be brought into siderurgy again for more valuable uses.

\section{Conclusion}

High natural radioactivity and low added value products that are produced to compensate that high radioactivity leads to the opening of an industrial proposal in which barn steel, from barns dismantled after liberty is granted to the cows, would be used for subcritical nuclear cores using locally mined uranium ore, after also the mining of $\mathrm{Pb}$ and $\mathrm{W}$ to shield the cores (typically available in surrounding areas of uranium ore). The Fermionic model presented in the second part of ${ }^{[8]}$ is appropriate (Pu239 will have to be added to the natural uranium fuel to start plutogenization) as the Fermionic binding creates a local supply of rapid neutrons in the core. This industrial proposal certainly would help the production of cheap electricity in regions also suffering from cold winters. The departure of the cows compensates for the weight of the metals, suggesting little to none contribution of magmatic neutrons to the cores, which anyway benefit from the $70 \%$ filling with light water only. Safety levels fall down as soon as the cores are opened for plutonium extraction.

\section{References}

[1]. Pirot F, "Spitting as traditional medicine" - why alpha-emitting nanoparticulates make spitting an unfortunate but significant contribution to health. Int $\mathrm{J}$ of Traditional and Complementary Medicine 2021; 6:33. DOI: 10.28933/ijtcm-2021-01-2306

[2]. Pirot F, Traumatic Brain Injury: a Case Report and Its Contribution to Understanding the Underlying Mechanisms - Alpha-Emitting Nanoparticulates Proven as Key, American $J$ of Medical Case Reports. 2020, 8(4), 100-102. DOI: 10.12691/ajmcr-8-4-2

[3]. Zaire R, Notter M, Riedel W, Thiel E. Unexpected rates of chromosomal instabilities and alterations of hormone levels in Namibian uranium miners. Radiat Res. 1997 May;147(5):579-84. PMID: 9146703

[4]. Pirot F, The shuriken effect of fertile alpha emitters : a physical process behind findings of chemical toxicity of depleted uranium. Int $J$ of
Nanoparticle Research, 2021; 4:15. DOI: 10.28933/ijonr-2021-03-1303

[5]. Pirot F, Volcanic Tephras and Human Energy Losses Together: The Real Source of Climate Change, Int J of Physics. 2019, 7(4), 126-134. doi: 10.12691/ijp-7-4-3

[6]. Barakat R, Oakley O, Heehyen K, Jooyoung J, CheMyong $\mathrm{J} \mathrm{K}$, Extra-gonadal sites of estrogen biosynthesis and function, BMB Rep, 2016, Sept 30, 49(9), doi: 10.5483/BMBRep.2016.49.9.141

[7]. A. M. Janczak, P. Torjesen \& S. Rettenbacher, Environmental effects on steroid hormone concentrations in laying hens' eggs, Acta Agriculturae Scandinavica, Section A - Animal Science, 2009, 59:2, 80-84, DOI: $10.1080 / 09064700903023348$

[8]. Pirot F, Useful concepts in magnetism, for supraconductivity and depleted uranium cleaning. Scientific Research and Reviews, 2021; 14:125. DOI: 10.28933/srr-2021-06-0203 